\title{
Effects of spatial pattern and relatedness in an experimental plant community
}

\author{
Ursula Monzeglio · Peter Stoll
}

Received: 18 December 2006/Accepted: 23 July 2007/Published online: 23 August 2007

(C) Springer Science+Business Media B.V. 2007

\begin{abstract}
Many plant species show limited dispersal resulting in spatial and genetic substructures within populations. Consequently, neighbours are often related between each other, resulting in sibling competition. Using seed families of the annuals Capsella bursapastoris and Stachys annua we investigated effects of spatial pattern (i.e. random versus aggregated) on total and individual performance at the level of species and seed families under field conditions. At the level of species, we expected that inferior competitors increase, while superior competitors decrease their performance within neighbourhoods of conspecifics. Thus, we expected a species by spatial pattern interaction. Sibling competition, however, might reduce the performance of competitors, when genetically related, rather than non-related individuals are competing. Therefore, aggregations at the level of seed families could decrease the performance of competitors. Alternatively, if the opposite outcome would be observed, kin selection might be hypothesized to have occurred in the past. Because heavy seeds are expected to disperse less than light seeds, we further hypothesized that kin selection might be more likely to occur in superior competitors with heavy, locally dispersed seeds (e.g. Stachys) compared to inferior competitors with light, more distantly dispersed seeds (e.g. Capsella). We found a significant species by spatial pattern interaction. Indeed, the inferior competitor, Capsella, showed increased reproductive biomass production in aggregated compared to random patterns. Whereas, the performance of the superior competitor, Stachys, was to some extent decreased by intraspecific aggregation. Although statistically not significant, effects of intrafamily aggregations tended to be rather negative in Capsella but positive in Stachys. Our results confirmed that spatial patterns affect growth and reproduction of plant species promoting coexistence in plant communities. Although, we could not provide strong evidence for sibling competition or kin selection, our results suggested that competition among relatives was more severe for Capsella (lighter seeds) compared to Stachys (heavier seeds).
\end{abstract}

U. Monzeglio $(\bowtie) \cdot$ P. Stoll

Department of Environmental Sciences, Section of Conservation Biology, University of Basel,

St. Johanns-Vorstadt 10, Basel, Switzerland

e-mail: u.monzeglio@unibas.ch 
Keywords Annual species · Coexistence - Competition · Kin selection · Resource partitioning

\section{Introduction}

Elucidating the many ways in which competing plant species manage to coexist is a major unresolved question in community ecology (Hutchinson 1961; Silvertown and Charlesworth 2001) and many hypotheses have attempted to explain the coexistence of species with similar life histories (see, e.g. Shmida and Ellner 1984; Chesson 2000a, b; Wright 2002; Barot 2004; Silvertown 2004). However, explaining how large numbers of competing plant species manage to coexist in the absences of obvious niche differentiation, conspicuous life history trade-offs (e.g. competition/colonization trade-off; Rees 1995; Turnbull et al. 1999, 2004) or evident disturbance (Connell 1978) remains challenging and controversial (see, e.g. Amarasekare 2003; Barot 2004; Silvertown 2004).

As a consequence of limited seed dispersal and/or clonal growth, most plant species aggregate intraspecifically, thereby increasing the importance of intra- versus interspecific competition (spatial segregation hypothesis, Pacala 1997). This is particularly relevant for sessile organisms where survivorship and fecundity are most affected by local population density rather than by the average global population density (Pacala and Silander 1985; Pacala 1997; Murrell et al. 2001). There is a large body of theory that underlines the importance of spatial pattern for ecological phenomena, such as coexistence and maintenance of biodiversity (Kareiva 1990; Bergelson 1990; Coomes et al. 2002; Bolker et al. 2003; Levine and Murrell 2003). However, compared to the large body of theory, there is still surprisingly little empirical evidence for the importance of spatial structure in shaping plant communities. Nevertheless, some experiments have shown that intraspecific aggregation might foster coexistence by allowing inferior competitors to increase their fitness (e.g. seed production). This might increase their persistence in the plant community and slow down competitive exclusion (Schmidt 1981; Bergelson 1990; Stoll and Prati 2001; Monzeglio and Stoll 2005). For example, if disturbances create gaps, inferior competitors might be able to colonize these gaps as long as they can produce enough seeds somewhere in the community. The few experimental studies that are available manipulated the spatial arrangement in an agricultural context (e.g. Harper et al. 1961; Brophy and Mundt 1991; Stauber et al. 1991; Norris et al. 2001). However, to our knowledge only one focused on natural communities (Turnbull et al. 2007). Therefore, the question to what extent and under which conditions intraspecific aggregation of species promotes coexistence by slowing down competitive exclusion remains controversial (Chesson 1991; Chesson and Neuhauser 2002; Murrell et al 2002; Bolker et al. 2003).

Spatially limited seed dispersal can lead to pronounced aggregation of conspecifics (see, e.g. Seidler and Plotkin 2006), with the additional consequence that neighbours are often genetically related (half- or full-siblings) to each other. In other words, when the prevailing pattern of dispersal results in relatives being aggregated in space and interacting primarily with one another, then local competition may become sibling competition (Cheplick 1992, 1993a, b; Kelly 1996; Lambin et al. 2001). Therefore, in plant species where dispersal is limited, the effects of spatial patterns (i.e. intraspecific aggregation) should not only operate at the level of species but also at the level of genotypes within species (Schmid 1990; Vuorisalo et al. 1997; Wilson and Nisbet 1997). 
In general, the intensity of competition is thought to increase with genetic similarity of the competitors (Maynard Smith 1978). This hypothesis, known as the resource-partitioning hypothesis (Young 1981; Argyres and Schmitt 1992), states that genetically variable offspring will experience less severe competition than genetically similar or identical offspring, because more diverse offspring are predicted to show greater ability to partition limiting resources. In addition, parents will leave fewer offspring if there is severe competition between their descendants (Maynard Smith 1978). Therefore, sibling competition can be broadly considered as negative interactions between genetically related individuals and should in principle be avoided (Cheplick 1992, 1993a, b).

Conversely, relatedness of individuals in a population may lead to kin selection (Hamilton 1964). The kin selection hypothesis predicts that individuals will behave altruistic, when $r b-c>0$, where $c$ is the fitness cost to the altruist, $b$ the fitness benefit to the beneficiary and $r$ is their genetic relatedness. In other words, an individual may behave altruistic (e.g. less competitive towards their relatives), even if the altruistic behaviour reduces its own fitness, if the costs are compensated with increased fitness of its relatives. In plant populations, kin selection may be a significant evolutionary force that counteracts sibling competition, because many species have limited seed dispersal (Goodnight 1985; Goodnight and Stevens 1997). Especially in plant species with heavy, locally dispersed seeds, local aggregation will increase sibling competition, but at the same time increase the potential for kin selection. On the other hand, in plant species with light far-dispersed seeds, seedlings are expected to be less aggregated and therefore sibling competition might occur less frequently. Thus, in plant species with frequent sibling interactions the possibility that kin selection might counteract potentially negative effects should not be excluded (Nakamura 1980; Cheplick 1993b; Kelly 1996; Griffin and West 2002). However, despite the straightforward predictions of the sibling competition hypotheses, few empirical tests have been made and the results are inconsistent. Amongst the studies, which investigated sibling competition in plants (Cheplick 1992), some showed that plants competing with genetically related individuals perform worse than plants competing with unrelated individuals (Willson et al. 1987; Kelley 1989; Argyres and Schmitt 1992; Karron and Marshall 1993). Others provide evidence that plants competing with genetic relatives outperform those competing with unrelated individuals (Willson et al. 1987; Tonsor 1989; Andalo et al. 2001; Donohue 2003). Hence, so far it remains difficult to unequivocally argue which of the both hypotheses is more likely to describe the dynamics of local competition in plant populations and communities.

The experiment reported here extends a previous spatial pattern experiment (Monzeglio and Stoll 2005) that assessed effects of intraspecific aggregation on species performance in experimental plant communities. The present experiment went further and aimed to evaluate effects of intraspecific aggregation at the level of seed families within species. Specifically, we collected seed families, which allowed us to assess not only effects of intraspecific aggregation but also effects of intrafamily aggregation on the growth and fitness of individuals. Based on our previous experiments, we expected that weak or competitively inferior species (e.g. Capsella bursa-pastoris) would produce more biomass when locally aggregated compared to randomly distributed and that intraspecific aggregation decreased biomass production of strong or competitively superior species (e.g. Stachys апnиa). In statistical terms, we expected a species by spatial pattern interaction.

Based on the sibling competition and the associated resource-partitioning hypothesis, we further expected that groups of relatives (i.e. intrafamily aggregation) would generally produce less vegetative and reproductive biomass compared to groups of non-relatives (i.e. intraspecific aggregation). In other words, biomass production in the intrafamily 
aggregation would be lower compared to the intraspecific aggregation. In contrast, if the opposite pattern would occur, than the operation of kin selection might be indicated. In this case, the performance of genetically related individuals would increase from intraspecific to intrafamily aggregations. Because Capsella has small and lighter seeds compared to Stachys, the former is expected to disperse its seeds less locally than the latter. Therefore, we hypothesized that kin selection might be more likely in Stachys where sibling competition should be more frequent compared to Capsella. Consequently we expected that intrafamily aggregation might be more likely to have positive effects in Stachys than Capsella.

\section{Materials and methods}

The purpose of this experiment was to investigate effects of spatial patterns (random versus aggregated) at the level of species (intraspecific aggregation) and seed families (intrafamily aggregation) within a species mixture under experimental field conditions [at the Research Institute of Organic Agriculture (FiBL), Frick, Switzerland]. We used four annual plant species (C. bursa-pastoris, S. annua, Stellaria media and Poa annua) representing common species composition in natural communities. Capsella and Stachys were the target species, while Poa and Stellaria were the matrix species. Seeds of the target species were collected from single mother plants grown in a previous experiment (Monzeglio and Stoll 2005) with a similar design as the present one. The mother plants were grown under four maternal treatments with different combinations of two spatial pattern (random versus aggregated) and two densities (low versus high). Seeds of the matrix species were obtained from a commercial seed supplier (Herbiseed, Wokingham, Berkshire, UK).

\section{Plant species}

Capsella bursa-pastoris L. (Brassicaceae) is a widely distributed, cosmopolitan annual pioneer species of disturbed ground and trampled sites. It forms rosettes with a multiflowered erect stem up to $40 \mathrm{~cm}$ high. Flowers are usually self-pollinated; however small insects (e.g. flies, small bees) visit the flowers. In disturbed European sites, greater levels of genetic heterogeneity have been recorded for populations sampled from recently cultivated than from non-cultivated sites (Bosbach and Hurka 1981), suggesting a positive relationship between the degree of environmental variability and genetic variation. Capsella reproduces entirely by seeds, which are small and light, dispersed by wind or rain drops. The majority of the seeds usually fall between 15 and $30(-50) \mathrm{cm}$ of the parent plant (Aksoy et al. 1998). Stachys апnиa L. (Lamiaceae) is an annual species with a multiflowered erect stem up to $40 \mathrm{~cm}$ high. This species grows for example in corn and tubercrop fields and gravel-pits. It prefers warm, dry and calcareous soils. Stachys is quite rare in most parts of Europe. It is predominately outcrossed and flowers from June to October. The hermaphroditic flowers are usually pollinated by hymenoptera, lepidoptera, or diptera. Although birds may disperse some seeds, Stachys seeds have no special structures aiding dispersal (e.g. elaisomes) and most of the relatively heavy seeds probably fall down in very close proximity of their mother plants. Stellaria media L. (Caryophyllaceae) is prostrate to ascending, with high-adventitious rooting and a height of up to $40 \mathrm{~cm}$. Poa апnиa L. (Poaceae) has adventitious roots at the first nodes and tillers up to $30 \mathrm{~cm}$ high and reproduces primarily by seeds. Stellaria and Poa are widely distributed, 
cosmopolitan annuals of disturbed habitats. Generally, C. bursa-pastoris, $P$. annua and $S$. media occur together.

\section{Collection of seed families}

Seed families of the target species Capsella and Stachys used in the present experiment were collected from mother plants grown in a previous spatial pattern experiment (see Monzeglio and Stoll 2005 for a detailed description of the experimental design) in which all four species (Capsella, Stachys, Poa and Stellaria) were grown in combinations of two different spatial patterns (random versus aggregated) and two different densities (low versus high). Since $P$. annua and $S$. media did not produce enough seeds, for the present experiment seeds were obtained from a commercial supplier (Herbiseed). Seeds of Capsella and Stachys were collected in summer 2002 and the maternal environments (spatial pattern and density) recorded. All seeds from a single mother plant are referred to as seed family and are at least half-sibs. We started the seed collection of Capsella on August 8, and mature seeds were collected daily until August 15. The last collection was done on September 11 when collection of the Stachys seeds started. In this case, in order to avoid too much seed loss, we collected the whole plant and separated the seeds later in the laboratory. These collections were done on September 20, October 1 and 8 and November 12. Seeds of each mother plant were counted mechanically (seed counting machine, Elomor) and the seed families with the largest number of seeds were chosen for the present experiment. In total, 36 seed families of Capsella (nine from random and aggregated low densities, and 18 from random high density) were used. For Capsella in aggregated high density no seed families produced enough seeds for the present experiment. As a result for the high density we had only mother plants grown in random spatial patterns. For Stachys, 36 seed families (nine from each of the four maternal treatment combinations) yielded enough seeds for the present experiment. Because the experiment had to be started, only the remaining seeds could be counted and weighed. The mean seed mass of Capsella was much lower than that of Stachys (Table 1). Capsella grown in aggregated patterns produced heavier seeds than Capsella grown in random spatial patterns $(t=2.21, d f=25$ and $P=0.037)$. Stachys did not show any significant differences in seed weight between mothers grown in random versus aggregated spatial patterns or at high versus low density. There was no significant interaction between maternal density and maternal spatial pattern $\left(F_{1,35}=1.4 ; P=0.253\right)$.

\section{Experimental design}

The experiment was designed as randomized split-plot and contained two blocks $(0.6 \times 6.0 \mathrm{~m}$, separated by $0.5 \mathrm{~m})$ each with six main plots $(0.6 \times 0.6 \mathrm{~m}$, separated by $0.3 \mathrm{~m}$ ). The three spatial pattern treatments (see below) were used as plot-level treatments yielding four replicates per treatment (two per block). The plots were subdivided into nine subplots $(0.2 \times 0.2 \mathrm{~m})$ that were divided in an upper and lower half, in such a way that each half contained $41 / 2$ subplots (the central subplot was halved) (Fig. 1A).

In order to avoid any misunderstanding about the spatial patterns of the present experiment (i.e. random, intraspecific and intrafamily aggregation) and spatial patterns in 
Table 1 Mean seed mass (mg) of Capsella bursa-pastoris and Stachys annua across seed families $(N=9)$ collected from individual mother plants grown in two different spatial patterns (random versus aggregated) and at two densities (low versus high)

\begin{tabular}{|c|c|c|c|c|c|c|c|}
\hline \multirow[t]{2}{*}{ Maternal density } & \multirow[t]{2}{*}{ Maternal spatial pattern } & \multicolumn{3}{|c|}{ Capsella bursa-pastoris } & \multicolumn{3}{|c|}{ Stachys аппиа } \\
\hline & & $N$ & Seed mass & $S E$ & $N$ & Seed mass & $S E$ \\
\hline \multirow[t]{3}{*}{ Low } & Random & 9 & 0.109 & 0.002 & 9 & 2.84 & 0.26 \\
\hline & Aggregated & 9 & 0.117 & 0.004 & 9 & 2.75 & 0.15 \\
\hline & Mean & & 0.113 & 0.002 & & 2.79 & 0.15 \\
\hline \multirow[t]{3}{*}{ High } & Random & 9 & 0.107 & 0.004 & 9 & 3.05 & 0.31 \\
\hline & Aggregated & 0 & & & 9 & 2.37 & 0.28 \\
\hline & Mean & & 0.107 & 0.004 & & 2.71 & 0.22 \\
\hline \multirow[t]{2}{*}{ Mean } & Random & 18 & 0.108 & 0.002 & 18 & 2.94 & 0.20 \\
\hline & Aggregated & 9 & 0.117 & 0.004 & 18 & 2.56 & 0.16 \\
\hline
\end{tabular}

For each spatial pattern/density combination nine different seed families were used (except for Capsella which had no seed families that produced enough seeds in high densities and aggregated pattern). For Capsella in high density and random pattern only nine, instead of 18, seed families had enough remaining seeds to be counted and weighed

$N$ number of mother plants or seed families, $S E$ standard error

which the mother plants grew (i.e. random and intraspecific aggregation, see Experimental design for maternal environment) we describe the main experimental design and the design corresponding to the maternal environment separately. We start with the spatial pattern of the present experiment.

In the present experiment, we used the four-species mixture and one density level (i.e. 100 seeds per cell, for a total of $40,000 \mathrm{seeds} / \mathrm{m}^{2}$ ). The three spatial pattern treatments were attained as follows. In the random pattern, 44 seeds of each of the nine seed families of Capsella and Stachys (i.e. for a total of $\sim 400$ seeds for each species) together with 400 seeds of Poa and 400 seeds of Stellaria were mixed and randomly scattered over the subplots, such that the individuals experienced inter- and intraspecific as well as intrafamily encounters at similar frequencies. In the aggregated patterns (i.e. intraspecific and intrafamily aggregated patterns), the subplots were further subdivided into 16 cells $(5 \times 5 \mathrm{~cm})$, and each cell contained only one species in such a way that individuals experienced more intra- than interspecific encounters. For the two species with seed families (Capsella and Stachys) seeds were aggregated at two levels. The first level consisted of groups of conspecifics, and will be referred to as intraspecific aggregation. In the intraspecifically aggregated pattern each cell contained $\sim 100$ seeds made up of 11 seeds from each of the nine seed families. The second level was made up of individuals of the same seed families and will be referred to as intrafamily aggregation. In the intrafamily aggregated pattern each cell contained 100 seeds from the same seed family in such a way that individuals in the centre of the cells competed only with genetically related individuals (Fig. 1A). Two seed families were used per species and subplot. The species and seed families were randomly allocated to the cells. For the species without seed families (Poa and Stellaria) each cell always contained 100 seeds sown as the intraspecific aggregations. 
(A) Experimental spatial pattern

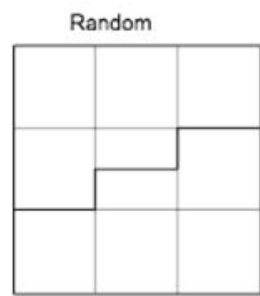

(B) Maternal environments

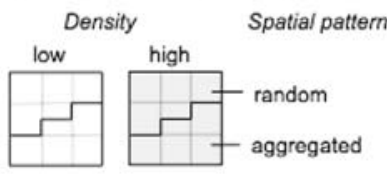

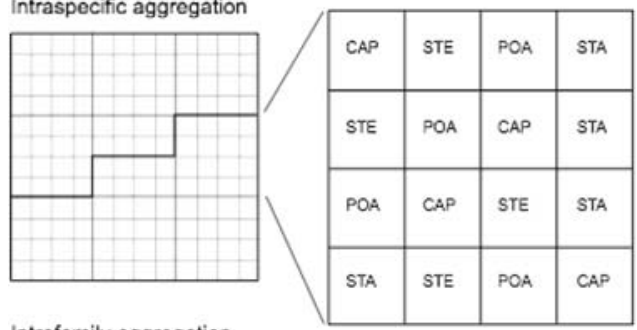

Intrafamily aggregation

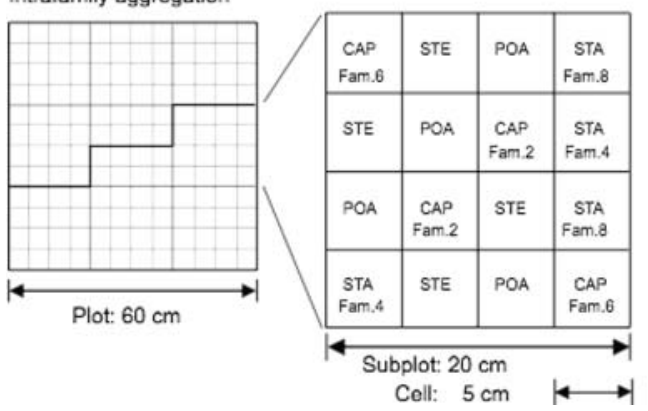

Fig. 1 Experimental design. (A) Experimental spatial pattern. Three different experimental spatial patterns, which varied at the plot $(60 \times 60 \mathrm{~cm})$ level, were realized as follows. In the random spatial pattern, 44 seeds from each of nine families of Capsella (CAP) and Stachys (STA) and 400 seeds of Poa (POA) and Stellaria $(S T E)$ were mixed and scattered over the subplots $(20 \times 20 \mathrm{~cm})$. In the intraspecific aggregation, subplots were further divided into 16 cells $(5 \times 5 \mathrm{~cm})$. Four randomly selected cells per species were sown with 11 seeds from each of nine families of Capsella or Stachys or 100 seeds of Poa or Stellaria. In the intrafamily aggregated pattern, two randomly selected cells were sown with 100 seeds from one seed family and two with 100 seeds from another seed family of Capsella or Stachys. The other two species (Poa and Stellaria) were sown as in the intraspecific aggregations. Spatial pattern were replicated four times (two randomly assigned within each of two blocks). (B) Maternal environments. The mother plants, from which seed families of Capsella and Stachys were collected, grew either in low or high density and random or aggregated patterns of a previous experiment. The maternal density (i.e. low versus high) was varied at the plot level, while the maternal spatial pattern (random versus aggregated) at the 'half-plot' level. One half (4 $1 / 2$ subplots) of each plot was sown with seeds from mothers grown in a random spatial pattern and the other half was sown with seeds from mothers grown in an aggregated spatial pattern. The maternal spatial pattern was randomly assigned

\section{Experimental design for maternal environment}

The density in which the mother plants grew was used as plot-level treatments. Each block contained six plots, i.e. three plots with seeds from mother plants grown at low and three 
plots with seeds from mother plants grown at high density. The spatial pattern in which the mothers grew was used as within-plot treatment (i.e. half-plot). Randomly allocated lower or upper halves were either sown with seeds from mothers grown in random or spatially aggregated patterns (for Capsella this was only possible for seeds from low-maternal densities and all seeds from mothers grown in high densities were from mothers grown in random spatial patterns) (Fig. 1B).

\section{Additional experimental settings}

In order to assess the germination activity of the seed families, simple germination trials with and without Gibberellic acid $(0.01 \%)$ both in the laboratory and in the field were carried out in May 2003. These experiments showed low-germination rates of field collected seeds without Gibberellic acid. Therefore, to increase germination, seeds of Capsella and Stachys were soaked in a solution of Gibberellic acid at $4-5^{\circ} \mathrm{C}$ for three to 5 days before sowing.

The blocks were established on May 16 and harvested in fall 2003. During the first month the two blocks were covered with a plastic tunnel (200 holes $/ \mathrm{m}^{2}$, GVZ-Bolltec, AG, Zurich, Switzerland) to protect the seedlings against sunlight and adverse weather. The tunnel was never completely closed, $20-30 \mathrm{~cm}$ from the ground were left open to permit the air to circulate and in July the tunnel was removed completely. Because of the heavy soil (high-clay content), each plot was covered with a layer $(2 \mathrm{~cm})$ of commercial garden soil before sowing to increase seed germination. The plots were sown between June 16 and 19 and watered with an automatic irrigation system (Gardena AG, Bachenbülach, Switzerland). The system was programmed to give rain-cycles of $1 \mathrm{~min}(\sim 11$ water $)$ starting at $5.15,6.15,7.15$ a.m., and $7.15,8.15,9.15$ p.m. The duration of the 9.15 p.m. rain-cycle was changed from 1 to 2 min on June 26. Because of the extremely hot summer 2003 on July 2 , one additional nozzle was positioned in the middle of each plot. These additional nozzles were programmed to give rain-cycles lasting 2 min starting at 8.30, 9.30, 12.30 a.m., and 4.30, 8.30, 9.30 p.m. and removed on July 29. After sowing, the seeds were covered by sieving a thin layer of commercial garden soil, which was slightly pressed down to prevent the seeds from being washed away. A snail fence enclosed the entire experimental field.

\section{Harvest}

The aboveground biomass of the four species was harvested at the subplot level $(0.2 \times 0.2 \mathrm{~m})$ between September 22 and October 15. Additionally, for the two species with seed families (Capsella and Stachys) the harvested biomass was separated into vegetative and reproductive parts and the total number of individuals was counted. Because Capsella started to produce mature seeds earlier, mature seeds were collected regularly from 25 July to 15 August 2003, and then added to the final reproductive biomass. The harvested biomass was dried for $12 \mathrm{~h}$ at $60^{\circ} \mathrm{C}$ and then stored. Before weighing, the biomass was dried again for $4-5 \mathrm{~h}$ at $60^{\circ} \mathrm{C}$. 
Statistical analysis

The data from Capsella and Stachys were analysed with a multi-factorial analysis of variance (ANOVA) for a split-plot design. Since maternal density, which varied at the plot level, never showed significant effects it was excluded from the analysis and ANOVA tables. Similarly, because maternal spatial pattern, which varied at the half-plot level, never showed significant effects, we pooled the data from the subplots at the plot level. That is, we summed the biomass and number of individuals of the nine subplots, and used the plots $(N=12$ with four replicates per spatial pattern) as experimental units. This pooling allowed us to simplify the ANOVA tables and the communication of the results but it did not change any of the reported results. Since we had no seed families for Poa and Stellaria, these species were considered as matrix species and not further analysed.

The spatial pattern treatments were tested against the plot-level residual mean square. In addition we used linear contrasts to separate them into (1) random versus aggregated (i.e. intraspecific and intrafamily aggregation), (2) intraspecific versus intrafamily aggregated pattern. There was one plot with a random spatial pattern treatment, in which the plants germinated particularly poorly or died soon after they germinated because of the extremely hot and dry weather. This was the only plot in which Capsella produced $<10 \mathrm{~g} / \mathrm{m}^{2}$ and the only plot in which biomass production of Stachys was less than the mean \pm 3 SE. As it turned out that Capsella produced less biomass in plots with random spatial patterns than aggregated plots, including this plot in the Capsella analysis rendered all effects more significant than reported. On the other hand, Stachys produced most biomass in the plots with random spatial patterns, except this particular one. Including this plot in the Stachys analysis increased the residual variation so much that all effects for Stachys became nonsignificant. Because the results of the analysis, especially for Stachys, changed significantly depending on whether we considered this plot or set the plot values as missing, we decided to present both analyses. The analysis in which the values for this unusual random plot were omitted is presented in the results (Table 3) and used to plot the charts. The analysis using all plots is presented as appendix.

We counted the number of seedlings 1 month after the beginning of the experiment and tested it as covariate. The covariate, however, had no significant effect and was consequently omitted. Even though the maternal environments had no significant effect on the main spatial pattern effect, we also tested initial seed mass for Stachys and Capsella as covariate. Again, the covariate had no significant effect and was omitted.

All data were expressed as number of individuals or grams per square metre for total biomass production or grams per individual for average biomass production. All biomass data were logarithmically transformed $\left[\log _{10}(\mathrm{Y})\right]$ to obtain normal distribution of the residuals and homogeneity of variances. Mean and SE from the analyses (back-transformed in the case of biomass) are presented throughout. All analyses were conducted using GENSTAT 5 (Payne et al. 1987).

\section{Results}

First of all, both species differed significantly in their overall performance (Table 2). Generally, total biomass production of Capsella was much lower $\left(18.9 \pm 4.0 \mathrm{~g} / \mathrm{m}^{2}\right.$, average \pm SE over 11 plots) than that of Stachys $\left(1,166.7 \pm 30.1 \mathrm{~g} / \mathrm{m}^{2}\right)$. The matrix species Stellaria produced $54.2 \pm 10.7 \mathrm{~g} / \mathrm{m}^{2}$ while Poa did not germinate. 


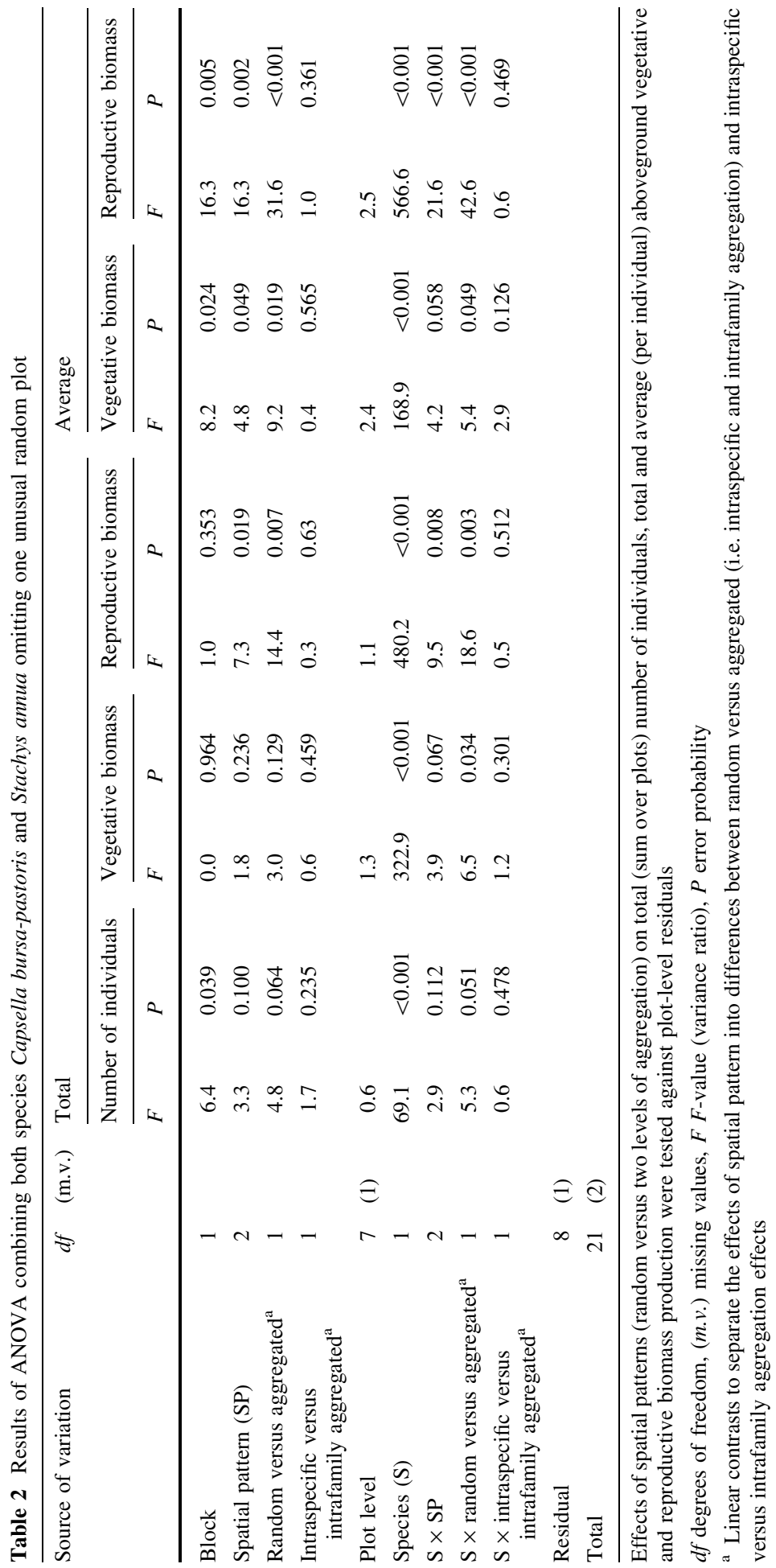




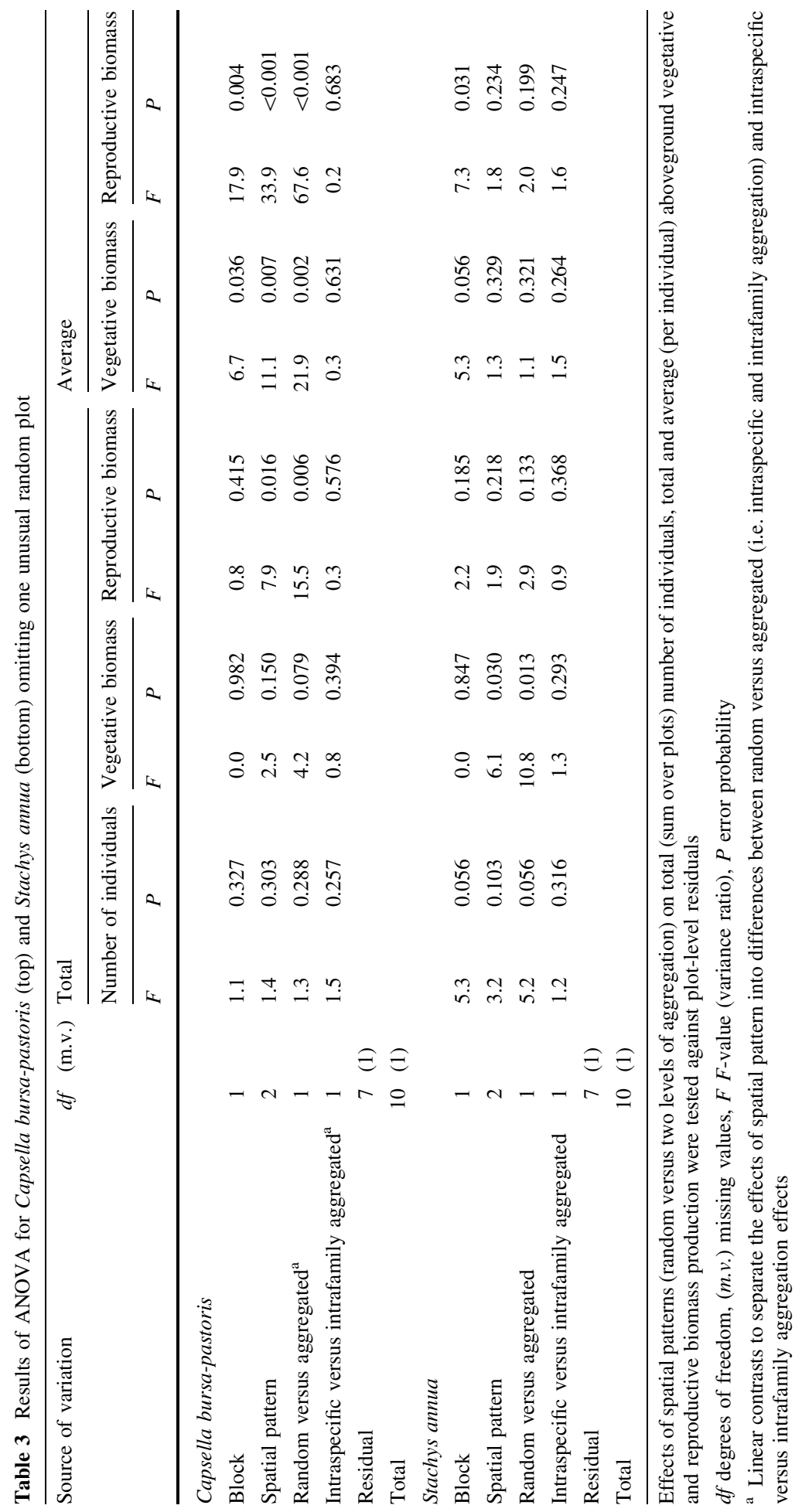




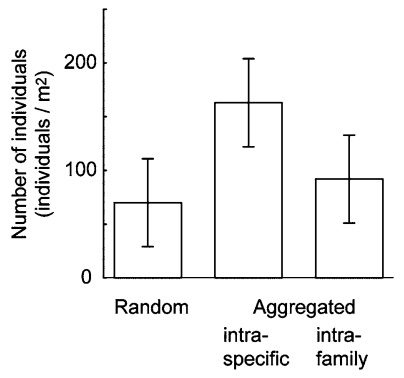

\section{Capsella bursa-pastoris}

Spatial pattern

Total biomass
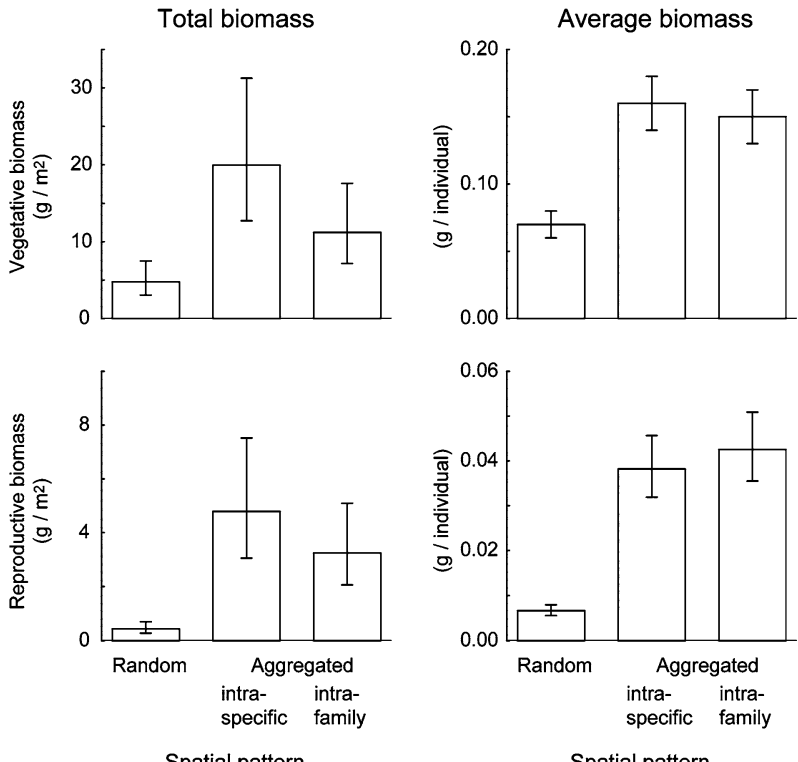

Spatial pattern

Spatial pattern

Fig. 2 Number of Capsella bursa-pastoris individuals (top), total (left, $\mathrm{g} / \mathrm{m}^{2}$ ) and average (right, g per individual) aboveground vegetative (middle) and reproductive (bottom) biomass grown in random, intraspecific or intrafamily aggregated spatial patterns. The bars represent mean \pm 1 SE from ANOVA for number of individuals and backtransformed means from $\log _{10}(\mathrm{Y})$-transformed data from ANOVA's for vegetative and reproductive biomass

The analysis including both species revealed a significant spatial pattern effect for total reproductive biomass and average vegetative and reproductive biomass (Table 2). For example, averaged over both species there was significantly more total reproductive biomass in the aggregated (intraspecific $46.9 \mathrm{~g} / \mathrm{m}^{2}$; intrafamily $39.9 \mathrm{~g} / \mathrm{m}^{2}$ ) than in the random patterns $\left(15.2 \mathrm{~g} / \mathrm{m}^{2}\right)$. There was a marginally significant species by spatial pattern interaction for total and average vegetative biomass and a significant interaction for total and average reproductive biomass (Table 2). The linear contrast showed that the main differences were between the random compared to the aggregated patterns.

Because the spatial pattern influenced the performance of the two species differently, we present species-specific results separately and begin with Capsella. Capsella generally had fewer individuals and produced less total and average biomass in the random compared to the aggregated patterns. The main spatial pattern effect was significant for total 
Fig. 3 Number of Stachys annua individuals (top), total (left, $\mathrm{g} / \mathrm{m}^{2}$ ) and average (right, $\mathrm{g}$ per individual) aboveground vegetative (middle) and reproductive (bottom) biomass grown in random, intraspecific or intrafamily aggregated spatial patterns. The bars represent mean $\pm 1 \mathrm{SE}$ from ANOVA for number of individuals and backtransformed means from $\log _{10}(Y)$-transformed data for vegetative and reproductive biomass

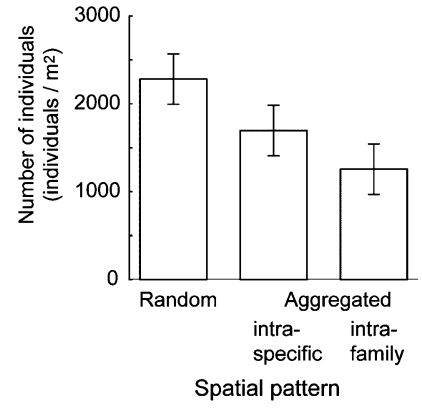

Total biomass
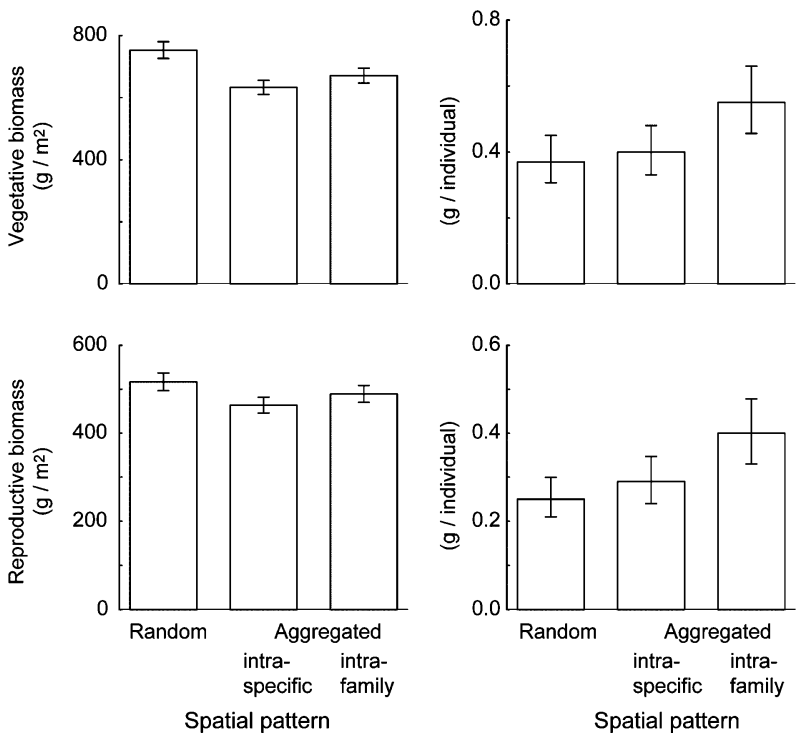

reproductive and average vegetative and reproductive biomass. The linear contrasts between random versus intraspecific and intrafamily aggregated pattern were highly significant. However, the differences between intraspecific versus intrafamily aggregated pattern were not significant (Table 3, Fig. 2). Although Capsella produced $\sim 70 \%$ less total vegetative biomass in the random compared to both (pooled) aggregated pattern, this effects was only marginally significant. The number of individuals was not significantly affected by the spatial pattern (Table 3, Fig. 2).

Stachys was less affected by the spatial pattern than Capsella. Nevertheless, Stachys had more but on average smaller individuals in random compared to both aggregated patterns. The main spatial pattern effect was not significant for the number of individuals, but the linear contrasts showed that Stachys had slightly more individuals in the random compared to the intraspecific and intrafamily aggregated pattern (Table 3, Fig. 3). Total vegetative biomass production of Stachys was significantly affected by the spatial pattern, with more total vegetative biomass in the random compared to both intraspecific and intrafamily 
aggregated pattern (Table 3, Fig. 3). The average vegetative biomass was not significantly affected by the spatial pattern. Total and average reproductive biomass of Stachys was not affected by the spatial pattern.

\section{Discussion}

Based on aboveground biomass production we defined $S$. annua as a strong and C. bursapastoris as a weak competitor. The weak competitor produced much more reproductive biomass per individual in aggregated compared to random spatial patterns. Because they also tended to be more numerous in aggregated compared to random spatial patterns, total reproductive biomass production was much higher in aggregated compared to random spatial patterns. Individuals of the strong competitor in contrast, were more numerous in random compared to the aggregated spatial patterns. However, individuals in random patterns tended to produce less vegetative and reproductive biomass per individual compared to individuals in aggregated patterns. Thus, Stachys almost exactly compensated for the different number of individuals such that there were only small and insignificant differences in the production of total reproductive biomass between the different spatial patterns $\left(516 \mathrm{~g} / \mathrm{m}^{2}\right.$ in random, 463 and $488 \mathrm{~g} / \mathrm{m}^{2}$ in intraspecific and intrafamily aggregated patterns, respectively). Interestingly, our findings showed, averaged over both species, an overall increase in total reproductive biomass in the aggregated compared to random pattern. This suggested that Capsella produced overproportionally more total reproductive biomass in the aggregated pattern than Stachys in the random pattern. This result further supports the notion that spatial structure seems to be relatively more important for small seeded (e.g. Capsella) compared to large seeded species (e.g. Stachys) (Monzeglio and Stoll 2005; Turnbull et al. 2007).

Our results for the weak competitor were generally consistent with previous findings (Stoll and Prati 2001; Monzeglio and Stoll 2005). They support our expectation that weak competitors increased their fitness (e.g. survival and seed production) within neighbourhoods of conspecifics compared to neighbourhoods of heterospecifics, at least in the short run. In addition, data on Stachys showed that intraspecific aggregation decreased the number of individuals and to some extent the performance of strong competitors. Thus, our results at the species level generally agreed with our earlier work on the effects of spatial patterns on species performance.

However, experimental studies like ours have the limitation that the absolute and relative densities of the species, the structure and scale of the plant community and the strength of competition are determined by the experiment rather than natural processes. In real communities, the degree of spatial aggregation is often less extreme and the spatial structure is more complex. Turnbull et al. (2007) quantified the effects of spatial structure on individuals, population and community biomass within a natural community of annuals. They found that the effects of spatial structure on total community biomass were relatively small. This was because common species have generally weak spatial structure and they draw down the effect on the community as a whole. Therefore, intraspecific aggregation as process that may delay competitive exclusion would be far more important for rare and weak (e.g. small seeded species) than for common and strong (e.g. large seeded species) competitors. Our results lend further support to this general conclusion, because spatial pattern effects for the small seeded species Capsella were much stronger than for the large seeded species Stachys. 
Our results at the level of seed families, however, were less clear and not statistically significant. Nevertheless, our results suggested, that effects of intrafamily aggregation differed depending on the species. Groups of relatives in the small seeded species (Capsella) tended to be less productive compared to groups of non-relatives in producing biomass. In particular, total reproductive biomass production in intrafamily aggregated patterns was only about half of that in intraspecifically aggregated patterns. This agrees with predictions from the sibling competition hypothesis and suggests that groups of relatives in Capsella indeed have a lower potential for resource partitioning than groups of non-relatives. For the large seeded species (Stachys), groups of relatives were slightly more productive compared to groups of non-relatives. Although the differences were not statistically significant, the general pattern agreed with our hypothesis that kin selection might be more likely to occur in plant species with heavy, locally dispersed seeds. Cheplick and Kane (2004) did a similar greenhouse experiment using Triplasis purpurea growing either alone or in inter- or intrafamily competition (note that what they call interfamily competition corresponds to our intraspecifc aggregated pattern). Their findings generally support the resource partitioning hypothesis. Similar to other studies (e.g. Taylor and Aarssen 1990; Donohue 2003), they showed, however, that the effects of neighbour relatedness on the growth and fitness differed among families. This suggests genetic variation of competitive ability among seed families. Contrary to Cheplick and Kane (2004), we could not obtain detailed information on the different competing seed families and our experiment was conducted under field conditions. To obtain information on the different competing seed families in the intrafamily aggregated pattern, we would have had to harvest the biomass at the cell level $(5 \times 5 \mathrm{~cm})$ rather than the subplot level $(20 \times 20 \mathrm{~cm})$. In addition, in the intraspecific and random pattern we would have had to label each individual seed in order to recover its family at harvest. This was impossible. However, we cannot exclude the possibility that one or more seed families performed better in the intrafamily compared to the intraspecific aggregation even though Capsella, on average, decreased its fitness in the intrafamily compared to the intraspecific aggregated pattern.

The very high density used in our experiment $\left(40,000 \mathrm{seeds} / \mathrm{m}^{2}\right)$ might be one reason for the prevailing effect of resource partitioning. Koelewijn (2004) investigated the effects of different densities on competing seed families and showed that density had stronger negative effects in absolute terms on the performance of the seed families and that the consequences of sibling competition depend on the frequency and relatedness of neighbours. Escarré et al. (1994) examined density effects and neighbour relatedness in a sib/non-sib competition experiment on the clonal Rumex acetosella. They found density-dependent effects of the degree of relatedness between plant individuals. At low densities, there were no growth differences, but when the density was doubled, the absolute sexual biomass was higher in non-sibs than in sib treatments, suggesting that competition was stronger between related plants. Therefore, we speculate that in our experiment, a lower density might have favoured the positive intrafamily effects observed in Stachys. In contrast, a higher density might have increased the negative effect of sibling competition observed in Capsella. Moreover, there is evidence that the effect of high relatedness may be modulated by the scale of competition (e.g. Queller 2004, Griffin et al. 2004, Frank 1998). Even if highly localized dispersal is likely to promote the evolution of altruistic behaviour (Hamilton 1964; Wilson 1987), the scale of competition may still play a major role. Limited dispersal may favour altruism because it increases relatedness between 
altruistic individuals. But it also increases relatedness between competitors, which opposes the selection for altruism (see, e.g. Taylor 1992; Wilson et al. 1992).

Both species in our experiment had fewer individuals in groups of relatives compared to groups of non-relatives suggesting that groups of related individuals suffered increased mortality compared to groups of non-related individuals. These results further suggested negative sibling competition effects, supporting the resourcepartitioning hypothesis and are in line with previous studies on sibling competition in plants (Willson et al. 1987; Kelley 1989; Argyres and Schmitt 1992; Karron and Marshall 1993). Within groups of related individuals, the strong competitor produced on average the highest individual biomass (vegetative and reproductive). However, because mortality was highest in intrafamily aggregations, and because there was no difference in the overall biomass production between groups of relatives and groups of non-relatives, we interpret this result as a simple density dependent effect rather than with kin selection.

Finally, alternative explanations for the relatively weak effects of spatial patterns at the level of seed families and different responses of the species to intrafamily aggregation must be considered. For example, there may be little or no genetic variation in our populations. Because we do not have any knowledge about the genetic variation in the different species we cannot really assess this possible explanation. Moreover, differences in seed weight of the two species do certainly not provide the only explanation for different responses to intrafamily aggregation. The different mating systems among the target species (i.e. highly selfing for Capsella and predominately outcrossing for Stachys) might provide an alternative explanation for some of the different responses of the species to intrafamily aggregation. That is, selfed seeds of Capsella are genetically more similar than outcrossed seeds of Stachys. Therefore, related individuals of Capsella might have suffered more intense sibling competition compared to Stachys, resulting in less resource partitioning and consequently reduced biomass production in intrafamily aggregations.

In summary, we provided further evidence that weak competitors increased their fitness within neighbourhoods of conspecifics compared to neighbourhoods of heterospecifics. In contrast, intraspecific aggregation decreased the performance of strong competitors. An additional aggregation at the level of seed families produced less clear results. Nevertheless, groups of relatives tended to perform worse than groups of non-relatives in Capsella whereas in Stachys, groups of relatives tended to perform slightly better than groups of non-relatives. Therefore our findings tended to support the resource partitioning hypothesis, rather than the kin selection hypothesis. However, there are many other factors (e.g. habitat selection) that may affect the way individuals interact and aggregate, and the circumstances under which neighbourhood competition between related individuals may lead to kin selection in plants remain largely unexplored. Thus, the consequences of genetic substructuring for species coexistence and its ecological and evolutionary implication in plant population dynamics merits further investigation.

Acknowledgements We thank Daniel Prati, David Murrell, Jürg Stöcklin and two anonymous reviewers for helpful comments on earlier drafts of this manuscript. Furthermore we thank the staff of the Research Institute of Organic Agriculture (FiBL) for much appreciated logistic support. This research was funded by the Swiss National Science Foundation (grant 3100-061572 to Peter Stoll) and supported by a grant of the Freiwillige Akademische Gesellschaft (FAG) Basel to Ursula Monzeglio. 


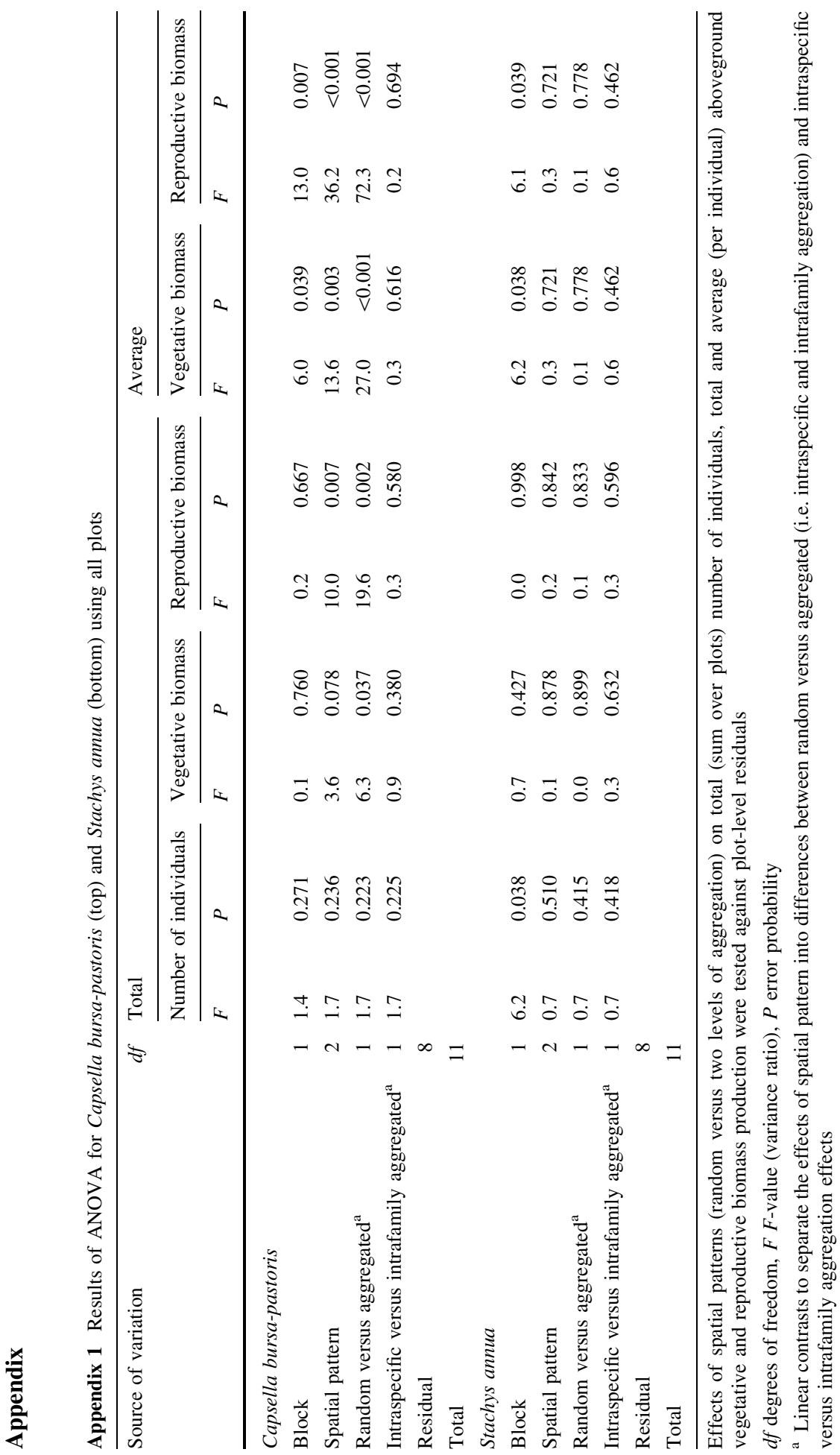




\section{References}

Aksoy A, Dixon JM, Hale WHG (1998) Capsella bursa-pastoris (L.) Medikus (Thlaspi bursapastoris L., Bursa bursa-pastoris (L.) Shull, Bursa pastoris (L.) Weber). J Ecol 86:171-186

Amarasekare P (2003) Competitive coexistence in spatially structured environments: a synthesis. Ecol Lett 6:1109-1122

Andalo C, Goldringer I, Godelle B (2001) Inter- and intragenotypic competition under elevated carbon dioxide in Arabidopsis thaliana. Ecology 82:157-164

Argyres AZ, Schmitt J (1992) Neighbor relatedness and competitive performance in Impatiens capensis (Balsaminaceae) - a test of the resource partitioning hypothesis. Am J Bot 79:181-185

Barot S (2004) Mechanisms promoting plant coexistence: can all the proposed processes be reconciled? Oikos 106:185-192

Bergelson J (1990) Life after death: site pre-emption by the remains of Poa апnиа. Ecology 71:2157-2165

Bolker BM, Pacala SW, Neuhauser C (2003) Spatial dynamics in model plant communities: what do we really know? Am Nat 162:135-148

Bosbach K, Hurka H (1981) Biosystematic studies on Capsella bursa-pastoris (Brassicaceae)—enzyme polymorphism in natural populations. Plant Syst Evol 137:73-94

Brophy LS, Mundt CC (1991) Influence of plant spatial patterns on disease dynamics, plant competition and grain-yield in genetically diverse wheat populations. Agric Ecosys Environ 35:1-12

Cheplick GP (1992) Sibling competition in plants. J Ecol 80:567-575

Cheplick GP (1993a) Sibling competition is a consequence of restricted dispersal in an annual cleistogamous grass. Ecology 74:2161-2164

Cheplick GP (1993b) Reproductive systems and sibling competition in plants. Plant Species Biol 8:131-139

Cheplick GP, Kane KH (2004) Genetic relatedness and competition in Triplasis purpurea (Poaceae): resource partitioning or kin selection? Int J Plant Sci 165:623-630

Chesson P (1991) A need for niches. Trends Ecol Evol 6:26-28

Chesson P (2000a) Mechanisms of maintenance of species diversity. Ann Rev Ecol Syst 31:343-366

Chesson P (2000b) General theory of competitive coexistence in spatially varying environments. Theor Popul Biol 58:211-237

Chesson P, Neuhauser C (2002) Intraspecific aggregation and species coexistence. Trends Ecol Evol $17: 210-211$

Connell JH (1978) Diversity in tropical rainforests and coral reefs. Science 199:1302-1310

Coomes DA, Rees M, Turnbull LA, Ratcliffe S (2002) On the mechanisms of coexistence among annual plant species, using neighbourhood techniques and simulation models. Plant Ecol 163:23-38

Donohue K (2003) The influence of neighbour relatedness on multilevel selection in the Great Lakes sea rocket. Am Nat 162:77-92

Escarré J, Houssard C, Thompson JD (1994) An experimental study of the role of seedling density and neighbour relatedness in the persistence of Rumex acetosella in an old-filed succession. Can $\mathrm{J}$ Bot 72:1273-1281

Frank SA (1998) Foundations of social evolution. Princeton University Press, Princeton, NJ

Goodnight CJ (1985) The influence of environmental variation on group and individual selection in a cress. Evolution 39:545-558

Goodnight CJ, Stevens L (1997) Experimental studies of group selection: what do they tell us about group selection in nature? Am Nat 150:S59-S79

Griffin AS, West SA (2002) Kin selection: fact and fiction. Trends Ecol Evol 17:15-21

Griffin AS, West SA, Buckling A (2004) Cooperation and competition in pathogenic bacteria. Nature 430:1024-1027

Hamilton WD (1964) Genetical evolution of social behaviour I and II. J Theor Biol 7:1-52

Harper JL, Mcnaughton IH, Sagar GR, Clatworthy JN (1961) Evolution and ecology of closely related species living in same area. Evolution 15:209-227

Hutchinson GE (1961) The paradox of the plankton. Am Nat 95:137-145

Kareiva P (1990) Population dynamics in spatially complex environments: theory and data. Philos Trans R Soc Lond Biol 330:175-190

Karron JD, Marshall DL (1993) Effects of environmental variation on fitness of singly and multiply sired progenies of Raphanus sativus (Brassicaceae). Am J Bot 80:1407-1412

Kelley SE (1989) Experimental studies of the evolutionary significance of sexual reproduction. 5. A field test of the sib competition lottery hypothesis. Evolution 43:1054-1065

Kelly JK (1996) Kin selection in the annual plant Impatiens capensis. Am Nat 147:899-918

Koelewijn HP (2004) Sibling competition, size variation and frequency-dependent outcrossing advantage in Plantago coronopus. Evol Ecol 18:51-74 
Lambin X, Aars J, Piertney SB (2001) Dispersal, intraspecific competition, kin competition and kin facilitation: a review of empirical evidence. In: Clobert J, Danchin E, Dhondt AA, Nichols JD (eds) Dispersal. Oxford University Press, Oxford, pp 110-122

Levine JM, Murrell DJ (2003) The community-level consequences of seed dispersal pattern. Ann Rev Ecol Evol Syst 34:549-574

Maynard Smith J (1978) The evolution of sex. Cambridge University Press, Cambridge

Monzeglio U, Stoll P (2005) Spatial patterns and species performances in experimental plant communities. Oecologia 145:619-628

Murrell DJ, Travis JMJ, Dytham C (2002) The evolution of dispersal distance in spatially structured populations. Oikos 97:229-236

Murrell DJ, Purves DW, Law R (2001) Uniting pattern and process in plant ecology. Trends Ecol Evol $16: 529-530$

Nakamura RR (1980) Plant kin selection. Evol Theor 5:113-117

Norris RF, Elmore CL, Rejmanek M, Akey WC (2001) Spatial arrangement, density, and competition between barnyardgrass and tomato. Weed Sci 49:61-68

Pacala SW (1997) Dynamics of plant competition. In: Crawley MJ (ed) Plant ecology. Blackwell Scientific, Oxford, pp 532-555

Pacala SW, Silander JA (1985) Neighbourhood models of plant population dynamics. 1. Single species models of annuals. Am Nat 125:385-411

Payne RW, Lane PW, Ainsley AE, Bicknell KE, Digby PGN, Harding SA, Leech PK, Morgan GW, Todd AD, Thompson R, Tunnicliffe Wilson G, Welham SJ, White RP (1987) GENSTAT 5 reference manual. Clarendon Press, Oxford

Queller DC (2004) Social evolution-kinship is relative. Nature 430:975-976

Rees M (1995) Community structure in sand dune annuals: is seed weight a key quantity? J Ecol 83:857-864

Schmid B (1990) Some ecological and evolutionary consequences of modular organization and clonal growth in plants. Evol Trend Plant 4:25-34

Schmidt W (1981) Über das Konkurrenzverhalten von Solidago canadensis und Urtica dioica. Verh Ges Ökol 9:173-188

Seidler TG, Plotkin JB (2006) Seed dispersal and spatial pattern in tropical trees. PLoS Biol 4:e344

Shmida A, Ellner S (1984) Coexistence of plant species with similar niches. Vegetatio 58:29-55

Silvertown J (2004) Plant coexistence and the niche. Trends Ecol Evol 19:605-611

Silvertown J, Charlesworth D (2001) Plant population biology. Blackwell Science, Oxford

Stauber LG, Smith RJ, Talbert RE (1991) Density and spatial competition of barnyardgrass (Echinochloa crusgalli) with rice (Oryza sativa). Weed Sci 39:163-168

Stoll P, Prati D (2001) Intraspecific aggregation alters competitive interactions in experimental plant communities. Ecology 82:319-327

Taylor DR (1992) Altruism in viscous populations - an inclusive fitness model. Evol Ecol 6:352-356

Taylor DR, Aarssen LW (1990) Complex competitive relationships among genotypes of 3 perennial grasses-implications for species coexistence. Am Nat 136:305-327

Tonsor SJ (1989) Relatedness and intraspecific competition in Plantago lanceolata. Am Nat 134:897-906

Turnbull LA, Rees M, Crawley MJ (1999) Seed mass and the competition/colonization trade-off: a sowing experiment. J Ecol 87:899-912

Turnbull LA, Coomes D, Hector A, Rees M (2004) Seed mass and the competition/colonisation trade-off: competitive interactions and spatial patterns in a guild of annual plants. J Ecol 92:97-109

Turnbull LA, Coomes DA, Purves DW, Rees M (2007) How spatial structure alters population and community dynamics in a natural plant community. J Ecol 95:79-89

Vuorisalo T, Tuomi J, Pedersen B, Käär P (1997) Hierarchical selection in clonal plants. In: de Kroon H, van Groendael J (eds) The ecology and evolution of clonal plants. Backhuys Publishers, Leiden, The Netherlands, pp 243-261

Willson MF, Thomas PA, Hoppes WG, Katusicmalmborg PL, Goldman DA, Bothwell JL (1987) Sibling competition in plants-an experimental study. Am Nat 129:304-311

Wilson JB (1987) Group selection in plant populations. Theor Appl Genet 74:493-502

Wilson WG, Nisbet RM (1997) Cooperation and competition along smooth environmental gradients. Ecology 78:2004-2017

Wilson DS, Pollock GB, Dugatkin LA (1992) Can altruism evolve in purely viscous populations. Evol Ecol 6:331-341

Wright SJ (2002) Plant diversity in tropical forests: a review of mechanisms of species coexistence. Oecologia 130:1-14

Young JPW (1981) Sib competition can favor sex in two ways. J Theor Biol 88:755-756 